See Article page e313.

\section{Commentary: Interleukin 2: The gasoline that lit the immunotherapeutic fire}

\author{
R. Taylor Ripley, MD
}

Ekeke and colleagues ${ }^{1}$ present an interesting report in which they develop a malignant pleural effusion model with Lewis lung cancer cells in mice with direct pleural injections of recombinant interleukin (IL) 2 on a vaccinia backbone. They found that direct administration of IL-2 to the pleural resulted in lower tumor burden and longer survival compared with systemic administration of IL-2. Next, they asked whether systemic programmed cell death protein (PD) 1 inhibition would augment the effects of intrapleural IL-2. They observed that the combination of intrapleural IL-2 with systemic PD-1 inhibition resulted in improved mouse survival compared with PD-1 inhibition alone. However, they noted that the combination approach did not improve the results of intrapleural IL-2 alone. These findings suggest that immunotherapy for malignant pleural disease may be an effective strategy, but direct pleural administration is likely more effective than systemic administration regardless of whether systemic treatment consists of IL-2 or PD-1 inhibition.

IL-2, originally described as T cell growth factor, is the first immunologic therapy to result in tumor regression. ${ }^{2}$ IL-2 is a cytokine that has a spectrum of immunological effects, including stimulation of cellular growth and terminal differentiation of lymphocytes. In the 1970s, IL-2 significantly advanced the study of the cellular immune system when its discovery enabled survival of ex vivo lymphocyte cultures. ${ }^{3}$ Subsequently, in 1984, the administration of IL-2 to a 33-year-old woman with metastatic melanoma resulted in survival for more than 30 years.

\footnotetext{
From the Division of General Thoracic Surgery, Department of Surgery, The Michael E. DeBakey Department of Surgery, Baylor College of Medicine, Houston, Tex. Disclosures: The author reported no conflicts of interest.

The Journal policy requires editors and reviewers to disclose conflicts of interest and to decline handling or reviewing manuscripts for which they may have a conflict of interest. The editors and reviewers of this article have no conflicts of interest.

Received for publication Nov 25, 2020; revisions received Nov 25, 2020; accepted for publication Nov 30, 2020; available ahead of print Dec 4, 2020.

Address for reprints: R. Taylor Ripley, MD, Division of General Thoracic Surgery, Department of Surgery, Baylor College of Medicine, 7200 Cambridge St, Suite

6A, Houston, TX 77030 (E-mail: R.Taylor.Ripley@bcm.edu).

J Thorac Cardiovasc Surg 2022;163:e329-30

$0022-5223 / \$ 36.00$

Copyright (c) 2020 by The American Association for Thoracic Surgery

https://doi.org/10.1016/j.jtcvs.2020.11.139
}

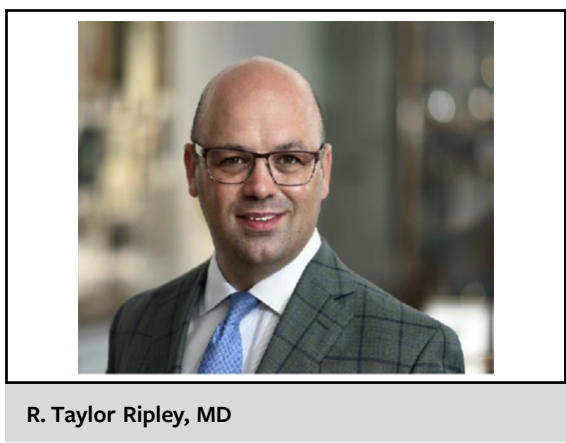

CENTRAL MESSAGE

Direct immunotherapy with IL-2

to the pleural space of mice with

malignant pleural lung cancer

resulted in tumor regression and

longer survival compared with

systemic immunotherapy

administration.

Her response to IL-2 was the first effective immunologic therapy administered to a human. To further test IL-2, an author on the current study (Lotze) reported that 20 patients with a variety of cancers were treated with IL-2. ${ }^{4}$ Although none of the patients experienced tumor regression, the authors did observe a 2- to 16-fold expansion of peripheral blood lymphoid cells, suggesting that IL-2 stimulated the immune system in vivo. These findings opened the door to immunotherapy as a potentially effective anticancer strategy. Currently, checkpoint inhibition by targeting PD-1, PD-ligand 1, or cytotoxic T-lymphocyte-associated protein 4 , as well as the adoptive immune transfer targeting cluster of differentiation 19 on B-cells are routinely administered.

The authors should be commended for executing an interesting approach to common problem without an effective, nonpalliative treatment. The direct pleural approach was effective regardless of administration of systemic immunotherapy. Additionally, IL-2 is a nonspecific $\mathrm{T}$ cell growth factor that resulted in tumor response. Whereas anti-PD-1 (or anti-PD-ligand 1 and anti-cytotoxic T-lymphocyte-associated protein 4) targets a specific receptor, similar to IL-2, these therapies are contingent upon naturally occurring $\mathrm{T}$ cells that recognize and kill a tumor cell. As immunotherapy advances, administration of genetically engineered $\mathrm{T}$ cells that directly target tumor antigens may be most effective as an intrapleural approach 
given that the pleural space may isolate this therapy from shared antigens. In conclusion, the authors utilize a strategy that has the ability to significantly influence patient care as immunotherapy continues to advance.

\section{References}

1. Ekeke CN, Russell KL, Murthy P, Guo ZS, Soloff AC, Weber D, et al. Intrapleural IL-2 expressing oncolytic virotherapy enhances acute antitumor effects and T cell receptor diversity in malignant pleural disease. J Thorac Cardiovasc Surg. 2022; 163:e313-28.

2. Rosenberg SA. IL-2: the first effective immunotherapy for human cancer. J Immunol. 2014;192:5451-8.

3. Morgan DA, Ruscetti FW, Gallo R. Selective in vitro growth of T lymphocytes from normal human bone marrows. Science. 1976;193:1007-8.

4. Lotze MT, Matory YL, Ettinghausen SE, Rayner AA, Sharrow SO, Seipp CA, et al. In vivo administration of purified human interleukin 2. II. Half life, immunologic effects, and expansion of peripheral lymphoid cells in vivo with recombinant IL 2. J Immunol. 1985;135:2865-75.
See Article page e313.

\section{Commentary: Regional oncolytics for pleural malignancies}

\author{
Alfredo Amador, $\mathrm{PhD},{ }^{\mathrm{a}}$ Alexander J. Byun, $\mathrm{MD},{ }^{\mathrm{a}}$ and \\ Prasad S. Adusumilli, MD ${ }^{a, b}$
}

Oncolytic viruses are genetically engineered, replicationcompetent viruses that preferentially infect, replicate within, and lyse cancer cells; released virions subsequently infect neighboring cancer cells, resulting in tumor regression. ${ }^{1,2}$ Two oncolytic viral therapies are currently in clinical use: H101, to treat head-and-neck squamous cell carcinomas in China, ${ }^{3}$ and talimogene laherparepvec, to treat late-stage melanoma in the United States. ${ }^{4}$ Expanded use of oncolytic viral therapy for other malignancies is constrained by the development of neutralizing antibodies following systemic administration of oncolytic viruses. ${ }^{2}$ We and others have studied measures to expand the efficacy of oncolytic viruses by delivering them regionally ${ }^{1}$ or by engineering them to express cytokines to modulate the tumor

From the ${ }^{\mathrm{a}}$ Thoracic Service, Department of Surgery; and ${ }^{\mathrm{b}}$ Center for Cell Engineering, Memorial Sloan Kettering Cancer Center, New York, NY.

Disclosures: P.S.A. has received research funding from ATARA Biotherapeutics and ACEA Biosciences; has served on the Scientific Advisory Board or as consultant to ATARA Biotherapeutics, Bayer, Carisma Therapeutics, Imugene, and Takeda Therapeutics; and has patents, royalties, and intellectual property on mesothelintargeted CARs and other T-cell therapies, method for detection of cancer cells using virus, and pending patent applications on T-cell therapies. All other authors reported no conflicts of interest.

The Journal policy requires editors and reviewers to disclose conflicts of interest and to decline handling or reviewing manuscripts for which they may have a conflict of interest. The editors and reviewers of this article have no conflicts of interest.

Received for publication Dec 1, 2020; revisions received Dec 1, 2020; accepted for publication Dec 2, 2020; available ahead of print Dec 8, 2020.

Address for reprints: Prasad S. Adusumilli, MD, Memorial Sloan Kettering Cancer Center, 1275 York Ave, New York, NY 10065 (E-mail: adusumip@mskcc.org).

J Thorac Cardiovasc Surg 2022;163:e330-1

$0022-5223 / \$ 36.00$

Copyright (c) 2020 by The American Association for Thoracic Surgery

https://doi.org/10.1016/j.jtcvs.2020.12.015
Check for updates

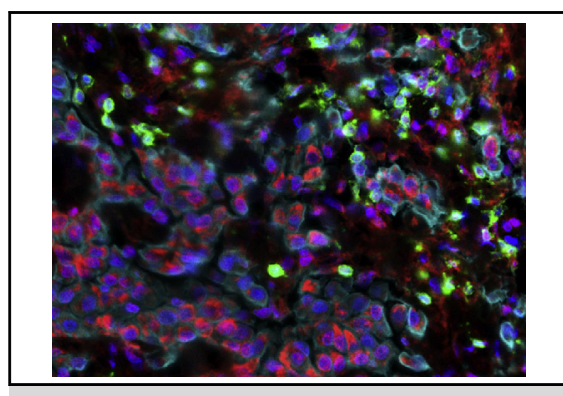

Pleural tumor with infiltrating $\mathrm{T}$ cells (green) following oncolytic viral infection (red).

CENTRAL MESSAGE

Intrapleural oncolytic virother-

apy is feasible, effective, and

augments antitumor immune

responses without systemic

toxicity in a preclinical model of

pleural malignancy.

microenvironment and promote immune responses. ${ }^{5,6} \mathrm{We}$ have translated the regional delivery of oncolytic vaccinia virus to patients with pleural malignancies (Figure 1). There has been renewed interest in oncolytic viral therapies following the discovery that checkpoint blockade immunotherapy can augment neoantigen responses generated by lysis of a subset of cancer cells by oncolytic viruses. ${ }^{8}$

In this issue, investigators from the University of Pittsburgh assess the safety, potency, and antitumor immune responses of an interleukin-2-expressing vaccinia virus $(\mathrm{VV}-\mathrm{IL}-2)^{6}$ in a preclinical model of malignant pleural disease. The authors hypothesize that intrapleural delivery of VV-IL-2 will limit IL-2 expression to the cell surface of the infected cancer cells, boost intratumoral immune responses, and avoid toxicity known to be associated with 